\title{
LA INVESTIGACION DE LOS TRIBUTOS EN LAS ADMINISTRACIONES LOCALES
}

\footnotetext{
Necesidad de organizar el Servicio de investigación. La investigación como función gestora: sistemas. El sistema español:

a) sistema represivo y de participación en las multas:

b) sistenia actual: principios que lo informan.

Actuación del personal inspector:

a) clases de actas.

b) el acta de invitación: su naturaleza.

Recargo del 10 por 100.

Casos en que no se aplica el recargo.

Impugnación del acta.

Personal inspector: su remuneración.

Penalidades: espiritu transigente y benévolo.

Conducta de los inspectores.

Derecho de consulta del contribuyente.

Tas calificaciones:

a) preceptos aplicables.

b) comprobación, ocultación y defraudación: cạracteres que las distinguen.

c) concepto fiscal de la reincidencia.

d) infracciones reglanentarias y defraudación.

Pago de las multas.

Derechos contra posibles extralimitaciones de la Adninistración.

Las garantías, en el proyecto de Código de Gobierno y Administración local.

Conclusión.
}

\section{Necesidad de organizar el Servicio de Investigación.}

Parrimos de un proyecto que aun no ha plasmado en realidades: el proyecto de Código de Gobierno y Administración Local, en cuyos artículos 1.029 y 1.042 se establece la diferenciación 'entre el deber de promover la inspección de sus tributos, que corresponde a las Administraciones locales, y el propiamente denominado Servicio de Inspección que cada Corporación debe organizar y llevar, con arreglo a sus medios. Porque, en efecto, la Administración está facultada para reclamar todos los datos, informes y documentos necesarios al exacto conocimiento de la base y a efectos de la liquida36 ción; pero al mismo tiempo necesita organizar y llevar un Servicio 
de Investigación que actúe inmediatamente cerca de la base y del contribuyente.

La novedad radica en el artículo 1.029 ; no en el 1.042 , que es reproducción de otros preceptos ya existentes.

Con arreglo a la legislación en vigor, el régimen a seguir en esta materia se regulará por los Ayuntamientos y Diputaciones, de acuerdo con los principios consignados en los Estatutos y en el Reglamento de Hacienda Municipal.

Las Diputaciones provinciales y los Ayuntamientos tienen, pues, el deber de promover la investigación de los tributos, a tenor de los artículos 99 del Reglamento citado y 285 del Estatuto provincial, cuyos textos concuerdan exactamente entre sí y con el Estatuto municipal en las bases que establecen para tan importante 'servicio; bases, no tan escasas como alguna vez se ha oído decir, que permiten su adecuado desarrollo en las Ordenanzas de exacciones o en las normas complementarias de ejecución del presupuesto. Llegado este momento, preciso es asomarse a las normas que rigen en la Administración económica del 'Estado, pues, por lo general, para la Hacienda estatal y para las locales suelen considerarse unos mismos principios, resultantes de la común orientación hacia el bienestar público y de la estructura análoga de las entidades de dereche público desde el punto de vista jurídico. La pereza y la rutina son las causas principales del absoluto abandono en que, en casi todas las Corporaciones locales, se encuentra la inspección de los tributos, muchas veces ni siquiera organizada, y otras, dotada de tan escasos medios, que difícilmente puede actuar de manera eficiente, olvidándose que para su florecimiento y prosperidad es precisa la función inspectora que, al mismo tiempo. persiga y descubra las ocultaciones maliciosas y guíe y eduque al contribuyente.

Las medidas fiscalizadoras han de estar siempre en relación íntima con el sistema impositivo imperante y el grado de la moral fiscal de la población. "La conciencia tributaria-dice Eheberg-no ha llegado a adquirir el grado de sensibilidad preciso, y la moral pública no la refuerza, pues ésta juzga las defraudaciones más benignamente que los delitos contra el patrimonio de los particulares." Es preciso, pues, educar la conciencia fiscal: a), mediante la imposición de multas; b), por el control administrativo-contable, y c), en todo caso, por la acción rápida y eficaz, a la par que educadora, del órgano inspector. Cuanto se insista sobre este último extremo-aspecto apremiante de la cuestión-para sacudir la pereza y la rutina, será dar un paso más en pro de "la deseada armonización" del inte- 
rés de las Haciendas locales "con el de los llamados a nutrirłas", si nos inspiramos en los mismos motivos que dieron vida en 1926 al Decreto de Bases para la inspección de los tributos de la Hacienda pública. Sin embargo, como no todo lo que es adecuado para el régimen económico del Estado puede tener aplicación a la Provincia y el Municipio (Borght), las Corporaciones que deseen obtener de esta sencilla exposición consecuencias prácticas de aplicación inmediata, deberán meditarla mucho antes de decidir.

\section{La investigación como función gestora. Sistemas.}

Ia inspección del tributo tiene por objeto la regularización y encauzamiento de las fuentes tributarias y el descubrimiento de las ocultaciones y defraudaciones (1), correspondiendo a un aspecto de las funciones propiamente denominadas de gestión (2), ejercidas por los organismos de la Administración provincial y central de la Hacienda pública. Corresponde al Ministro la alta inspección y suprema iniciativa, y a los Directores generales, de un modo directo y especial, la dirección del Servicio de Investigación. Las oficinas inspectoras provinciales funcionan bajo la autoridad inmediata de los Delegados de Hacienda, a los que corresponde la constante y permanente inspección de los tributos en la provincia de su jurisdicción, y en ellas hay un Inspector-Jefe y varios Inspectores de las diferentes especialidades: Ingenieros industriales, Profesores mercantiles y Diplomados del Cuerpo general, que ejercen sus funciones permanentemente en todo el territorio de la provincia a que se hallan afectos, con la obligación de dar un rendimiento mínimo de trabajo. Estos funcionarios son considerados, cuando actúan en el ejercicio de sus funciones, como agentes de la Autoridad, y van provistos de un carnet que los acredita en el ejercicio del cargo; al realizar los servicios de comprobación e investigación, se presentan en el local donde el contribuyente ejerce la industria, y después de darse a conocer, proceden a levantar la correspondiente acta, que se cursa inmediatamente a la Administración de Rentas públicas para la práctica de la liquidación que proceda.

Los Inspectores del tributo realizan, por tanto, actos de comprobación e investigación cerca del contribuyente que están prohibidos a los negociados de gestión de la oficina liquidadora. A las actas acompaña la información necesaria para que el expediente pueda ser

(1) Artículo 15 del Reglamento para el ejercicio de la Inspección de la Hacienda pública, de 13 de julio de 1926 .

(2) Artículo $1 .^{9}$ del Reglamento de procedimiento en las reclamaciones económico-administrativas de 29 de julio de 1924 . 
exactamente calificado por la Administración a efectos de la liquidación de cuotas y penalidades que en su caso se deriven de aquéllas.

Tal distinción entre la función investigadora y los actos de calificación y liquidación, a cargo de oficinas diferentes y funcionarios distintos, es peculiar de nuestro derecho financiero, tan diferente en éste como en otros aspectos de la mecánica fiscal a lo que suele hacerse en otros países, Alemania e Italia por ejemplo, donde los mismos negociados que liquidan son los que realizan las inspecciones necesarias.

Siguiendo las orientaciones del Reglamento de la Inspección de la Hacienda pública, el artículo 1.041 del Proyecto de Código de Gobierno y Administración Local dice: "Los expedientes de defraudación e infracción se iniciarán por el Servicio de Inspección o por acción pública, y su tramitación hasta el fallo firme deberá llevarla por separado el Organismo administrativo correspondiente, cuyos funcionarios, en ningún caso, podrán tener participación en las multas":

Nos dice Griziotti que para la inspección de los tributos en Italia, las leyes conceden a los procuradores del impuesto y a los funcionarios fiscales amplias facultades para reclamar documentos y datos y ejercer el necesario control para llegar al más exacto conocimiento de la base imponible.

Los correspondientes negociados, al efecto de la investigación, pueden: requerir de las oficinas públicas los extractos de documentos que necesiten; hacer comparecer al contribuyente para aclarar dudas y para que aporte pruebas; entrar en los locales destinados al ejercicio de industrias y comercios; llamar a cualquier individuo apto para aportar nuevas informaciones; inspeccionar los libros de contabilidad de las sociedades en general y de los particulares que, por precepto de la Ley, tengan obligación de llevar libros en forma, tales como los comerciantes mediadores, notarios, agentes de cambio, etc.; obligar a presentar los títulos representativos de rentas en sumas determinadas; tener en cuenta el valor en alquiler de la vivienda del contribuyente como indicio de su modo de vivir.

Los medios de indagación del Fisco se refuerzan con la institución de la policía tributaria, que es un Cuerpo de investigación o inspección para el conocimiento de los elementos necesarios para la comprobación de las denuncias de los contribuyentes (Real Decreto de 3 de enero de 1926, número $3 .^{\circ}$ ). Cuando las informaciones no concuerden, los procuradores del impuesto invitan al contribuyente a dar la oportuna explicación o a hacer la debida rectificación, o bien 
le notifican sin más trámites la base imponible y el impuesto que se le ha fijado.

Si el contribuyente acepta las bases fijadas por el Fisco, se logra el acuerdo; en otro caso, las partes pueden llegar a una 'transacción mediante un concordato. Si éste no se llega a establecer, el contribuyente puede recurrir, en el caso de impuestos sobre los negocios. a la autoridad de grado superior al funcionario contra quien se recurre, esto es, al Intendente de Hacienda o al Ministro de Hacienda; en el caso de impuestos directos, a la Comisión censual para el impuesto territorial, y a la Comisión administrativa para los otros impuestos directos del Estado. Terminado el recurso en vía administrativa, se puede apelar a la autoridad judicial, una vez publicada la matrícula y pagado el importe impugnado.

El sistema italiano difiere mucho del español. Los reformadores de 1845 implantaron, al mismo tiempo que el sistema francés de 'as contribuciones directas, una institución peculiarisima de la constitución administrativa francesa: su Inspección; y, como se dice en la Memoria de la Dirección general de Contribuciones de 1913, “jamás, desde que la Inspección se destaca en Francia como función diferenciada de la mera acción auxiliar del Ministro, ha dado aquella organización en el extremo, solamente explicable por el predominio que en nuestro país ha ejercido siempre una consideración formalista de las instituciones administrativas, de privar a las grandes ramas de la Administración de la Hacienda de una acción interna y propia de inspección". Sin embargo, con la legislación posterior, el órgano al que se ha encomendado una adecuada sustitución, ha llegado a adquirir el vigor que requiere su funcionamiento normal.

\section{El sistema español. a) Sistema represivo y de participación en las multas.}

De la Memoria de la Dirección general de Rentas públicas sobre la gestión económico-administrativa realizada durante los años de 1926 y 1927, reproducimos los siguientes párrafos:

"Al comenzar el año 1926, los servicios de la Inspección en general, y particularmente los de la Inspección de los tributos, no había vencido todavía el período de crisis que se inició con la reorganización administrativa del Ministerio de Hacienda, realizada en junio de 1924, y por virtud de la cual, la Inspección general de la Hacienda pública quedó suprimida y atribuídas sus funciones a las Direcciones generales de Rentas públicas y de Tesorería y Contabilidad" (3).

(3) L.a Inspección general de Hacienda fué restablecida por Ley de 3 de 40 septienıre de 1941 , correspondiendole inspeccionar todos los servicios depen- 
"Reunidos en el primero de estos Centros los servicios que antes se repartían las Direcciones generales de Contribuciones, Propiedades y Timbre, se vió todavía recargado con función tan delicada y extensa, y tan necesitada de una atención escrupulosa y perseverante, como es la 'Inspección de los tributos. La extensión misma y la multiplicidad y diversidad de los servicios fueron causa del retraso en su organización definitiva, y así, durante los meses que siguieron a la reforma de 1924, continuaron desarrollándose según las normas reglamentarias de antes establecidas, sin que fuera posible otro esfuerzo que el de evitar su paralización y estancamiento, y sin que, por tanto, hubiera espacio ni ocasión para intentar las innovaciones y mejoras que la opinión y el mayor perfeccionamiento del propio servicio demandaban."

"La nueva separación de las Direcciones generales, realizada al finalizar el año 1925, estableciendo una división más lógica del trabajo, permitió ya acometer esta reforma, de tantos años pedida sin que jamás, sin duda por la dificultad de sacudir el peso de una larga tradición, fuese intentada con el propósito firme y radical que demandaban los principios en que la actuación inspectora venía inspirándose."

"Era unánime la opinión, al juzgar este sistema, que ni en el propio Ministerio hallaba el calor de una defensa nacida de la convicción; pero que subsistía, sin embargo, por una mezcla de inercia, de rutina $\mathrm{y}$ desconfianza en los otros procedimientos propugnados."

"Y como la protesta era constante y no podía ser tachada de injusta, fué frecuente el caso de que los Gobiernos tratasen de aten-

dientes de este Departamento, y al colocarla bajo la inmediata direccion del Subsecretario, que en este aspecto tiene el carácter de Inspector general, queda asegurada "una beneficiosa unidad de criterio y de acción en .su funcionamiento", a la vez que se afianza la efectividad de su accion con la creación del cargo de Subinspector general con rango y categoria de Director general. Al fraccionamiento de la función inspectora entre los distintos centros directivos, ha sustituído el sistema que la experiencia venía recomendando como más eficaz, y que tiene sus antecedentes más próximos en el R. D. de 10 de abril de 1917. Desde 1845, la tendencia legislativa se halla alternativamente informada por los dos sistemas, constituyendo unas veces la Inspección un organismo independiente, y encarnando otras en las funciones reconocidas a los Directores generales. Claro es que hasta la fecha no ha dispuesto el Ministerio de inspectores rigurosamente seleccionados, capaces de actuar en todos los ramos de la Administración fiscal, y que hizo posible la transcendental reforma.

Conocimiento de la situación real de todos los servicios: laboratorio del que pueden salir en lo sucesivo los trabajos preparatorios para el perfeccionamiento de la compleja máquina administrativa; observación directa del trabajo de los organismos y funcionarios gestores; estadística de recaudaciôn, como antecedente de una politica recaudatoria... Tales son, entre otros, los cometidos es: pecificos de la Inspección generai de Hacienda, como elementos de un todo que so encamina claramente a conseguir el más elevado rendimiento de los organismos ejecutores. 
derla, sobre todo en los últimos tiempos, en que aquélla había adquirido serios caracteres de gravedad, más acentuados por el acrecentamiento hasta límites extraordinarios de las multas y de la consiguiente participación en ellas de los Inspectores."

"Sin embargo, nada fundamental, nada verdaderamente hondo y renovador se intentó. Las reformas realizadas fueron parciales, de carácter puramente accidental y accesorio: escala proporcional regresiva en las participaciones de los Inspectores; facilidades para relamar que se dieron a los contribuyentes; facilidades, también, de consulta concedidas a los mismos y obligación de contestarles de oficialmente, establecida para la Administración; y, sobre todo, nueva caracterización de los hechos constitutivos de ocultación o defraudación."

"En este último punto se halla indudablemente el origen de las diferencias que durante tantos años han tenido alejados e imposibilitados de comprenderse, al contribuyente y a la Administración, que aquél veía encarnada en el Inspector. Es evidente que el daño económico causa un malestar agudo, inmediato, originario muchas veces de trastornos graves; pero el daño moral, si no siempre ocasiona crisis en tal grado de agudeza, opera en cambio más profundamente, alcanza capas más hondas en el espíritu, y su acción, no por lenta es menos transcendente. Al contrario, como procede por acumulación, llegado el día del desbordamiento, la crisis que en el transcurso del tiempo ha ido fraguándose, se produce en forma difícil ya de contener o de encauzar."

"Este fué, precisamente, el caso de la Inspección: el sistema represivo, único intentado durante tantos años, había llegado a producir ese estado de opinión a que antes se alude y que se traducía en la constante protesta de los elementos por él afectados. Las clases industriales y mercantiles, por medio de las entidades que las representan, o individualmente en muchos casos, hicieron llegar con reiteración al Poder público su queja por tal estado de cosas, su aspiración vehemente a un cambio radical en los procedimientos, su protesta, con frecuencia airada, por lo que llegaron a considerar y a calificar como atropello y vejamen por parte de la Administración."

"Y no puede sorprender ciertamente que se haya llegado a ese extremo, cuando se considera que el sistema adolecía de dos errores fundamentales: basaba su propósito educador del contribuyente tan sólo en el castigo, y aseguraba la eficacia y la moralidad del organismo inspector con su participación, en cada caso, en la multa impuesta." 
"El castigo, empleado de una manera sistemática, no ha producido jamás el saludable efecto educador que con él se perseguía. $Y$ esto, que tan real y verdadero. es en todos los aspectos de la vida, alcanza caracteres de axioma al referirse a fines fiscales. Nadie tiene más fina percepción de los sentimientos de justicia que el contribuyente a quien se exige un sacrificio económico en favor del Estaro."

"Reconocen todos la obligación sagrada de contribuir, pero se sienten lastimados si en la exigencia de esta obligación no presiden normas de equidad. La suma, la acumulación de estas lastimaduras, es casi siempre origen de la protesta exteriorizada colectivamente."

"Tal fué el caso de este procedimiento de investigar tantos años practicado sin que se notase disminución apreciable en la ocultación. Al contrario, una de las manifestaciones más frecuentes de la protesta del contribuyente que, sin razón ni fundamento en la mayoría de los casos, se consideraba atropellado por la Inspección, era la de su reiteración en la burla de la Ley fiscal. $\mathrm{Y}$ así ha podido verse cómo una y otra vez el contribuyente contumaz era expedientado en sucesivas visitas, porque, terminada cada una de ellas, se apresuraba a presentar la baja por el mismo concepto que la Inspección lo había llevado a tributar, o, aprovechando las enseñanzas que de aquélla recibía, disfrazaba hábil y convenientemente su contabilidad:"

"El procedimiento, pues, daba resultados opuestos diametralmente a los perseguidos, ya que en vez de crear un ambiente de cordialidad entre el contribuyente y el Fisco y de fomentar en aquél el sentimiento del deber fiscal y la consiguiente lealtad en sus relacionés con la Administración, despertaba una especie de rencorosa animosidad. que tenía fiel reflejo en ese propósito deliberado de defraudar y en la satisfacción que el éxito de la habilidad producía en el que acertaba a realizarla."

"El mal era agravado todavía por la concurrencia del otro error fundamental del sistema: la participación del Inspector en la multa. Es innegable,que en la inmensa mayoría de los casos el Inspector procedió bajo el antiguo sistema con toda corrección, como fiel cumplidor de sus deberes, siempre ingratos. $\mathrm{Y}$ sin embargo, su trabajo, su sacrificio en muchos casos, no encontraba la simpatía y el aliento, sino que, por el contrario, se veía constantemente envuelto en una atmósfera de hostilidad y suspicacia que alcanzaba también a la función ejercida y a la Administración representada por él."

"La culpa de tal estado de cosas no fué, pues, suya; 'fué simplemente de los reglamentos sucesivos, que no acertaron a distinguir, 
por razones fundamentales y de esencia, la diferencia que existe entre el contribuyente que peca por ignorancia. por negligencia o por: contagio, al ver que otros proceden mal y alardean de ello sin sufrir daño, y el que consciente y deliberadamente sustrae al Tesoro lo que le es 'debido, para lograr así un beneficio doblemente ilegítimo e inmoral, ya que no sólo lo obtiene en perjuicio del Estado, sino también de los otros contribuyentes similares, cumplidores del deber fiscal, que así quedan en condiciones de inferioridad notoria para el desarrollo de su vida mercantil, gravada con un gasto obligado que el defraudador rehuye. En ese sistema, unos y otros, los buenos y malos contribuyentes, tenían pena semejante, ya que desde el Real Decreto de 14 de noviembre de 1899 venía incorporado a nuestra legislación el principio de la calificación de la responsabilidad y de sa graduación, según que el interesado se conformase o no con el expediente incoado."

"No era, pues, extraño aquel temor, mezclado de animosidad, con que la Inspección era recibida en todas partes, ni puede mostrarse sorpresa ante la enemiga del contribuyente, que, al enterarse por el propio Inspector de las responsabilidades pecuniarias que se le iban a exigir, veía cifrada con toda claridad la parte de ellas que había de ser cobrada por el 'mismo funcionario que lo visitaba, que descubriera la ocultación presunta y que la ponía en conocimiento de la Administración. Ante el interés personalísimo y directo que en aquel acto tenía el Inspector, no era fácil que el contribuyente creyese en su desprendimiento, por fortuna para la Hacienda tantas veces probado, ni en su serenidad de juicio y su espíritu de equidad."

"Se imponía, pues, acometer la reforma de este servicio, tan esencial en toda Hacienda, que sin él no puede concebirse que los tributos lleguen a dar su propio rendimiento, ni los contribuyentes a conocer en la debida extensión sus deberes para con el Fisco. $Y$ al hacerlo, era preciso tener presente las reclamacions, las solicitudes, ya añejas, de las clases por la Inspección más frecuentemente afectadas, y que bien pudieran concretarse en la desaparición de estos dos errores-el castigo como sistema y la participación en la multaque antes se han señalado."

Sistema actual: Principios que lo informan.

Los principios que informan hoy el funcionamiento de tal servicio en el Estado, son:

a) El personal inspector no tiene participación directa ni indirecta en las multas que se impongan en los expedientes incoados por 
su iniciativa. Un personal bien retribuído y responsable cumple mejor sus funciones, sin malquistarse con los contribuyentes.

b) Este personal actúa con sujeción a normas reglamentarias concretas. El que la Administración, en el ejercicio de sus funciones fiscalizadoras, entrabe la circulación y se inmiscuya con frecuencia en la esfera de la actividad privada, supone, como elemental exigencia de derecho, que sus atribuciones estén perfectamente determinadas por la Ley fiscal.

c) En toda actuación inspectora se ilustra al contribuyente sobre los recursos y reclamaciones que puede interponer. Complemente obligado del segundo principio es que los contribuyentes gocen de amplia prerrogativa para repetir contra los actos de la Administración.

d) La contrainspección alcanzará a todos los Inspectores del tributo. Los funcionarios inspectores deben ser intervenidos merced a formalidades contables y por la acción contrainspectora, minuciosamente reglada. (Hoy no es sino una aspiración, plasmada en la Ley de 28 de marzo de 1941.)

c) La colaboración del contribuyente con el Fisco se logra por una labor educadora, de carácter permanente, tan recomendada por los Centros directivos, y con un sistema de penalidades.

El R. D. de 30 de marzo de 1926 estableció las bases a que había de acomodarse la inspección del tributo, señalando un cambio radical en los procedimientos. En el Reglamento de 13 de julio siguiente, y. Inego en sucesivas Circulares, se delineó el sistema, perfeccionado por el R. D. de 22 de octubre y R. O. de 19 de noviembre de igual año. Es en estas últimas disposiciones donde, de una manera total y definitiva, se suprimió la participación de la Inspección en las multas.

El acta de invitación, creada por R. $O$. de 23 de septiembre de 1927, varió el procedimiento de actuación cerca de los contribuyentes que no han cumplido sus obligaciones fiscales.

Decía el Sr. Calvo Sotelo a los Delegados de Hacienda en carta circular de 13 de abril de 1926, con motivo del radical cambio que en el régimen de la Inspección suponía la aplicación del $R$. D. de 30 de marzo anterior: "Lo que sí creo preciso, antes de terminar, es indicarle la conveniencia de que haga comprender al personal de la Inspección que ahora más que nunca está en el deber de trabajar en beneficio del Tesoro. Resultaría de un deprimente efecto moral que ctrando ha desaparecido el estímulo personal y directo de las multas, se debilitase la eficacia de la gestión inspectora. Eso sería tanto como dar la razón a las clases contribuyentes, que de modo tan reiterado 
han venido sosteniendo que los Inspectores procedían tan sólo movidos por su interês inmediato...". Y en el preámbulo de la mentada disposición puede leerse :"Ese contacto entre dos intereses, que por una mala inteligencia sin fundamento, aunque tradicionalmente admitida, se consideran opuestos y en pugna, requiere ser sometido a reglas que eviten en lo posible los rozamientos y malas interpretaciones a que tan ocasionado ha sido siempre”".

\section{Actuación del personal inspector. a) Clases de actas.}

Los Inspectores, al realizar los servicios de comprobación e investigación, pueden levantar tres modelos de actas, diferentes por su estructura y consecuencias:

El acta de presencia, modelo 8, en caso de conformidad con lo declarado por el contribuyente, sin sanción alguna (4).

El acta amarilla de invitación, modelo 14 , con recargo de un 10 por 100 sobre las cuotas que por consecuencia de ella se liquiden.

El acta blanca. de constancia de hechos, modelo 9, cuando no proceda la de invitación, y que puede dar origen a un expediente de ocultación o de defraudación e imposición de multas.

La actuación de los Inspectores se limita al levantamiento de las actas, a suministrar al contribuyente las explicaciones que desee respecto a su caso y a pasar aquéllas, acompañadas de su informe, a la Administración de Rentas Públicas.

Esta dependencia incoa de oficio el oportuno expediente, lo califica y dicta el acto administrativo, que es notificado al particular por la Inspección.

\section{b) El acta de invitación: Su naturaleza.}

A partir de la R. O. de 23 de septiembre de 1927, los Inspectores inician su actuación cerca de los contribuyentes que no han cumplido sus obligaciones fiscales, invitándoles a rectificar su situación tributaria. Si la invitación es aceptada por el contribuyente, se hace constar en "acta de invitación", modelo 14, amarilla, que la Inspección pasa a la Administración de Rentas Públicas para su liquidación y trámite. Tales actas tienen la consideración de declaraciones o "partes de alta", si están autorizadas con la conformidad del contribuyente, y hasta fecha reciente no podía imponerse penalidad alguna por los hechos en ella reflejados. Cuando no existe conformidad entre la Inspección y el contribuyente, o cuando éste ofrece resistencia, o cuando es reincidente, el inspector procede a levantar "acta

(4) Eiste modelo no se utiliza, por haber cáído en desuso. 
de constancia de hechos", modelo 9, blanca, con arreglo a lo prevenido en el artículo 61 del Reglamento.

Por su naturaleza, el acta de invitación ha de responder siempre a la realidad de un descubrimiento practicado por el inspector, merced a actos de gestión personal y directa. Proceder en otra forma - Circular número 9 de 28 de septiembre de 1927-, aparte de la indelicadeza que supondría, habría de resultar perjudicial y contraproducente, conduciendo de modo inevitable a la desaparición de derechos que sólo pueden estar basados en la confianza nacida de una conducta extremada en la corrección y hasta en el escrúpulo. Como justificante de esta gestión personal y directa, sólo puede admitirse la existencia del acta de invitación. modelo 14 , creada por $R$. O. de 23 de septiembre de 1927, o bien la de constancia de hechos, modelo 9 del Reglamento, y, por consiguiente, sólo en las liquidaciones a que las mismas se refieran, reconocen las Administraciones de Rentas Públicas a la Caja Central la participación reglamentaria, cuando procede.

La Dirección general de Rentas Públicas ha emitido el siguiente juicio sobre el acta de referencia (5):

"El "acta de invitación" supone un llamamiento a la cordialidad entre los contribuyentes y la Administración y resuelve íntegramente el problema de las calificaciones, estableciendo la debida y justa diferencia entre el contribuyente de buena y de mala fe; entre el que se muestra dispuesto a cumplir con sus deberes fiscales y el que los rehuye deliberadamente:"

"En esta forma, no podrá ser nunca tachado de defraudador el que sólo pecó por olvido, por desconocimiento o por abandono. Existirá el castigo que supone el satisfacer los débitos de una sola vez, si esto le significa un verdadero quebranto económico; pero no pesarán sobre él, a la par, el calificativo y la multa, que quedan para aquéllos otros cuyo deseo de escapar a la común y patriótica carga fiscal, aparezca demostrado y reiterado."

Es indudable que la Orden de creación del acta de que se trata. se halla inspirada en un amplio sentido de generosidad. Esta actitud

(5) Memoria de 1927. Por el artículo 142 de la Ley de Reforma Tributaria de 16 de diciembre de 1940 se suprimio la Dirección general de Rentas públicas, creándose:

a) La Dirección general de Contribuciones Industrial y de Utilidades, a la que incumbira la gestión de los tributos expresados en su título.

b) La Dirección general de Contribuciones sobre la Renta, que tendrá a su cargo la formación y conservación del Registro de Rentas y Patrimanios $y$ cuanto ataña a la contribución sobre la Renta.

c) La Dirección general de la Contribución de Usos y Consumos, aue cuidara de la gestión de este tributo. 
de protección educadora, que intenta persuadir y at:aer antes de castigar, es la que corresponde a la misión tutelar del Estado.

\section{Recargo del 10 por 100}

Entre otras consideraciones que fundamentan la Ley de 28 de marzo de 1941, figura la "conveniencia de contrarrestar prácticas abusivas de la llamada acta de invitación", llamada a desaparecer según se desprende del. sentido literal del articulado, cuando dice: "...en tanto se mantenga en vigor...". A todas las actas levantadas a partir del 16 de abril de dicho año se aplican los preceptos de esta Ley, $\mathrm{y}$, por tanto, las cuotas reflejadas en aquéllas sufren un recargo del 10 por 100 , para el Tesoro, cuando sean autorizadas con la conformidad del contribuyente, girado, por lo menos, sobre la cuota anual, cuando se trate de contribuyentes cuyas tarifas consignen las cuotas por año.

\section{Casos en que no se aplica el recargo.}

Excepcionalmente, dicho recargo no se aplicará en los siguientes casos:

a) Cuando en el acta se reflejen bases impositivas conocidas por la Administración, en su concepto y cuantía, por declaración o documentos presentados por el contribuyente con el fin de liquidar la contribución y concepto a que el acta se contraiga.

b) Cuando el contribuyente se hallare matriculado con clasificación fijada por la propia Administración, en virtud de consulta:

\section{Impugnación del acta.}

A tenor del artículo $2 .^{9}$ de la Ley de 28 de marzo de 1941, las actas de invitación autorizadas con la conformidad del contribuyente no podrán ser impugnadas por éste, que, no obstante, podrá reclamar en vía económico-administrativa contra los acuerdos dictados por la Administración como efecto del acta, en cuanto no sea consecuencia legal de dicho documento.

\section{Personal inspector: Su remuneracion.}

A tenor del artículo 99 del Reglamento de Hacienda Municipal, la Administración municipal tiene el deber de promover la investigación de los tributos, a cuyo efecto puede reclamar todos los antecedentes y documentos necesarios de los particulares, autoridades y funcionarios de cualquier orden. Igualmente corresponde a dicha

$4 \%$ Administración imponer las sanciones corrrespondientes en los ca- 
sos de ocu'tación o de defraudación. (Igual al 285 del Estatuto provincial.)

Pero no se puede promover la investigación de los tributos sin disponer del personal idóneo necesario y sin montar una oficina de Inspección en la Administración local.

Consecuencia de las disposiciones legales dictadas en 1926 para la Hacienda estatal, fué el concurso-oposición para conceder 200 diplomas de aptitud para el ejercicio de la inspección. La base 13 del Real Decreto de 30 de marzo estableció como condición precisa para poder ejercer el cargo de Inspector del tributo, la de pertenecer a alguno de los Cuerpos técnicos de la Hacienda, o la de poseer el diploma de aptitud que al efecto se creó para los funcionarios del Cuerpo general.

No fué ésta una de las disposiciones que menos transcendencia tuvieron entre las contenidas en el Decreto de reorganización de la Inspección. Su alcance mismo, las nuevas normas que se establecían, hicieron preciso un órgano adecuado que ofreciese las más sólidas garantías de competencia y moralidad. El resultado obtenido superó en mucho a todas las esperanzas que en la reforma se habían puesto, y ello, sin duda alguna, es debido en buena parte a la selección de personal realizada.

Fueron, pues, abolidas las participaciones en las multas como medio de remuneración de los inspectores, conservándose, en cambio, el estímulo preciso para mantener vivos su actividad y celo, a cuyo efecto se estableció un sistema de participaciones con cargo a la Caja Central de la Inspección, que se nutre en la actualidad del 20 por 100 del importe de las cuotas descubiertas ingresadas en el Tesoro. Estos fondos los administra el Comité Central, creado por R. D. de 30 de marzo de 1926 y reorganizado por Orden de 16 de febrero de 1938, y Decreto de 24 de febrero de 1941. Se niega participación a la Inspección en los casos señalados en el artículo 92 del Reglamento (6).

Al establecer las normas de distribución de ese fondo común se tuvieron en cuenta dos circunstancias esenciales para asegurar la pureza y la eficacia de la actuación inspectora. En primer término, se

(6) Esto es, cuando la Inspección no haya descubierto la ocultación y se haya limitado a comprobar su existencia en virtud de ordenes o informes de la Superioridad; cuando, por el largo tiempo transcurrido, se aprecie en la resolución que hubo apatía o negligencia en el funcionario de la Inspección, y cuando se haya encomendado a un agente especial el descubrimiento de la oculzacion. 
atendió a que todos los encargados de realizarla gozasen de medios económicos suficientes para desenvolverse en la vida sin agobios, y a tal fin, se les asignó una gratificación fija equivalente a la mitad de su sueldo; y en segundo lugar, se procuró estimular su trabajo, tan difícil, delicado y poco grato, con participaciones proporcionales a las cantidades que por cuotas hiciesen ingresar en el Tesoro.

Se hizo girar esta participación sobre las cuotas precisamente para huir de uno de los aspectos que más contribuyeron a la odiosidad generalmente despertada por la Inspección: el de las multas. En la forma determinada por el Decreto, la penalidad resultaba indiferente al Inspector, que así no tenía interés alguno en su imposición ni en su cuantía, circunstancia que forzosamente había de aumentar las garantías de imparcialidad en su actuación.

El Código de Gobierno y Administración Local sigue en este aspecto la orientación del antiguo sistema de participación en las multas, al decir en su artículo 1.040: "Las Corporaciones locales podrán establecer, dentro de un límite máximo de 25 por 100, la participación de los Inspectores y denunciantes en las multas que se hagan efectivas por defraudaciones e infracciones".

\section{Penalidades: Espíritu transigente y benévolo.}

Las penalidades se aplican por las oficinas de Hacienda con arreglo a lo dispuesto en los reglamentos; en general, se castiga la ocultación con multa equivalente al tanto de la cuota liquidada, y la defraudación, con multa del duplo al triplo de la misma. Los expedientes de comprobación no llevan afecta ninguna responsabilidad.

La Administración de Rentas públicas es la oficina encargada de calificar los expedientes y de practicar las liquidaciones. El Ministerio de Hacienda tiene muy recomendado que los expedientes incoados a consecuencia de la gestión inspectora, cuando no obedezcan a actas de invitación, se consideren y tramiten en su inmensa mayoría como de ocultación. Con ello la Administración da muestras de su espíritu transigente $\mathrm{y}$ benévolo, no debiendo considerarse como de defraudación sino en casos muy caracterizados, en los que concurran circunstancias de notoria gravedad, de reincidencia o de patente e indiscutible mala fe (Cir. de 21 de agosto de 1926). Los expedientes que tienen su origen en acta de invitación sólo pueden dar lugar al recargo del 10 por 100 , que no tiene el carácter de multa.

Este mismo espíritu de transigencia se advierte en nuestro Derecho municipal. Así, el artículo 95 del Reglamento de Hacienda mu50 nicipal recomienda que en los procedimientos sobre investigación de 
los tributos cuiden-los Ayuntamientos "de acomodarlos al principio de un gran respeto al contribuyente", y que no se impongan multas y penalidades "más que en aquellos casos en que haya existido manifiesto propósito de eludirlos". He aquí un motivo más de identidad entre la Administración de la Hacienda pública y las Administraciones locales.

\section{Conducta de los inspectores.}

Dispone el artículo 95 del Reglamento de Hacienda municipal: "Sin perjuicio de lo que establece el Estatuto municipal, los Ayuntamientos, al fijar en las Ordenanzas de exacciones los procedimientos sobre investigación de tributos, cuidarán de acomodarlos al principio de un gran respeto al contribuyente, dentro de la inflexibilidad en la exigencia de su pago, de modo que ningún contribuyente deje de satisfacer a los fondos municipales el total de las cargas que le corresponda, sin ser objeto de multas y penalidades más que en aquellos casos en que haya existido manifiesto propósito de eludirlos".

"Los contribuyentes que, declarando sus bases de imposición, consulten por escrito a la Administración municipal para que les señale la clasificación o base tributaria que en lo sucesivo les corresponda y la acepten provisionalmente, sin perjuicio de su derecho a discutirla, quedarán exentos de responsabilidad, aunque dicha clasificación resultare insuficiente o errónea."

El párrafo primero de este artículo refiérese -a la conducta del Inspector.

En el ejercicio de sus funciones-dice la base 33 del R. D. de 30 de marzo de 1926 y el artículo 71 del Reglamento de la Inspección-observarán los Inspectores del tributo la más exquisita cortesía, sin que en ningún caso dejen de guardar a los contribuyentes y al público en general, las mayores consideraciones, cuidando, muy especialmente, de enseñar a aquéllos sus deberes tributarios, aconsejándoles la conducta que deben seguir en sus relaciones con la Administración y apoyando sus razones con textos legales.

El espíritu que informa este precepto se renueva en la exposición del R. D. de 22 de octubre de 1926 y halla su amplio desarrollo en las circulares números 3,6 y 10 de 20 de noviembre de 1926, 25 de mayo de 1927 y 12 de enero de 1928, de las que entresacamos los siguientes párrafos:

"Es preciso, en una palabra, que la función tutelar del Estado, no aparezca desfigurada y contrahecha por la actuación inspectora, sino que a través de ella, se manifieste clara y serenamente, por el 
empleo constante de procedimientos persuasivos, de una gran corrección, de la transigencia, compatible con el cumplimiento del deber, y de una exquisita pureza."

Aspiración constante del Inspector ha de ser " la de conseguir que en el ánimo de las personas a quienes se acerque en cumplimiento de su difícil misión, quede firmamente grabado el convencimiento de que han tratado con un caballero, dando a esta palabra todo su valor, en lo que significa de cortesía, honorabilidad e inteligencia".

" "Procediendo con este criterio y aplicando a sus relaciones con el contribuyente las más rígidas leyes de la cortesía y el honor, ès seguro que los Inspectores lograrán, en poco tiempo, que desaparezca, totalmente, el equivocado concepto que, aunque en menos extensión que antes, más circunscrito y reducido a las zonas más alejadas de la Administración, subsiste todavía, y por el cual la Inspección se presenta como enemiga y perseguidora del contribuyente. La lealtad. la cordialidad y el desinterés en las relaciones con él, destruirán bien pronto ese funesto prejuicio..."

\section{Derecho de consulta del contribuyente.}

El segundo párrafo del artículo 95 del Reglamento de Hacienda Municipal, es una copia exacta del párrafo tercero del 280 del Estatuto Provincial, y éste, a su vez, transcripción literal del número priméro del artículo 14 de la ley de Reforma tributaria de 26 de julio de 1922, que, a continuación, regula el procedimiento para que los contribuyentes puedan utilizar tal derecho. A su tenor, toda persona que esté sujeta al pago de cualquier contribución o impuesto o que pueda estarlo, tiene derecho a acudir a la Delegación de Hacienda de la provincia respectiva, a fin de que se le manifiesten sus obligaciones tributarias. A tal efecto, presentará instancia con su copia, reintegradas ambas con timbre de 25 céntimos y escritas a media columna, consignando con claridad y precisión los hechos de que se trata. El jefe de la respectiva dependencia, sin otro trámite que el sucinto informe del funcionario correspondiente, devolverá al interesado la aludida copia, en la que se expondrá concisamente los preceptos de aplicación y sus deberes tributarios. Cuando por falta de antecedentes de hecho no pueda evacuarse la consulta, se dirá así en la copia de la instancia, expresando lo que fuere necesario conocer. Las contestaciones de los jefes de dependencia no tendrán el carácter de actos administrativos, pero siempre que no se haya cometido fal-

52 sedad ni omisión en la relación de los elementos contributivos no po- 
drá exigirse responsabilidad alguna al contribuyente que hubiere formulado la consulta y viniere tributando con arreglo a las instrucciones que se le hubieren dado en virtud de las mismas.

$\mathrm{Y}$ claro es que donde dice la ley "Delegación de Hacienda" podemos nosotros decir "Ayuntamiento" o "Diputación Provincial".

\section{Las calificaciones: a) Preceptos aplicables.}

Las regula el art. 96 del Reglamento de Hacienda Municipal, que es reproducción del 281 del Estatuto Provincial. Dice así:

"En los casos de investigaciones de los tributos y de responsabilidad por las ocultaciones y defraudaciones a que dé lugar, se entenderá:

A). Que existe mera omisión cuando el contribuyente haya dejado de presentar parte de los documentos justificativos de sus declaraciones o de consignar en ellas elementos contributivos.B) Que existe ocultación cuando el contribuyente, sin haber sigilado el elemento primordial de tributación, hubiere incurrido en omisión o inexactitudes accidentales o de cuantía que no produzcan en la liquidación de la cuota diferencia de más de un tercio; y C) Que existe defraudación cuando el contribuyente haya ocultado la integridad de los elementos de tributación o parte de ellos que exceda de la cuantía señalada en el párrafo anterior.

En el primer caso se procederá a rectificar el error u omisión cometidos sin exigir responsabilidad alguna; en el segundo, la penalidad se fijará en la tercera parte de la multa que corresponda en el supuesto de defraudación, y en la tercera la sanción consistirá en la totalidad de las multas autorizadas en las Ordenanzas respectivas."

\section{b) Comprobación, ocultación y defraudación: Caracteres que las distinguen.}

Es difícil, en extremo, por no decir que imposible, fijar a la ocultación y a la defraudación caracteres suficientemente concretos y específicos que las distingan, no sólo en términos legales, sino también, morales, puesto que en realidad no son más que grados de una culpa del mismo carácter. Diversos reglamentos y disposiciones lo han hecho, fijándose más bien en aspectos puramente externos, más fáciles para la clasificación, puesto que, generalmente, 'se reducían a una cuestión de plazo o de conformidad, que en lo que en el acto, objeto del expediente, había de esencial.

La ley reguladora de la Contribución sobre las Utilidades de la riqueza mobilaria, con un sentido más moderno y más profundo de 
las cosas que el resto de la legislación tributaria española, ha venido a entenderlo así al suprimir la ocultación y sustituírla por la omisión.

En esta forma, la buena y la mala fe de los contribuyentes, el acto del que delinque por ignorancia o abandono y el de quien con plena conciencia trata de burlar la Ley rehuyendo su obligación fiscal, tienen el castigo adecuado y proporcionado.

Este principio, tan justo y equitativo, es el que se recogió después para la Hacienda Pública en el Reglamento de 1926 al definir - respetando las definiciones parciales de los demás-en términos de generalidad, los caracteres de la comprobación, de la ocultación y de la defraudación. No se consideró conveniente eliminar la ocultación de entre las calificaciones reglamentarias, tanto por el respeto ya indicado que se guardó a los distintos Reglamentos vigentes, como por la conveniencia de graduar la culpa. Lo que se hizo, sobre todo por medio de instrucciones sucesivas a las oficinas provinciales, fué variar el contenido de aquella palabra, y, sobre todo, introducir definitivamente la comprobación entre las calificaciones, con caracteres tan extensos como fueron necesarios para eximir de responsabilidad a quienes no hubieran demostrado propósito de defraudar.

En la Administración de la Hacienda Pública, por lo tanto, los expedientes que se incoen a consecuencia de actos de ivestigación del tributo se calificarán con arreglo a lo que dispongan las leyes $\mathbf{y}$ reglamentos por que se rijan las contribuciones o impuestos a que correspondan. En términos generales, según el artículo 56 del Reglamento de la Inspección, serán:

a) De comprobación:

1. Cuando presentadas el alta o la declaración, consten en ella todos los elementos sujetos a tributar.

2. Cuando los contribuyentes tengan declaradas sus bases contributivas.

3. Cuando el contribuyente no haya variado su industria desde la última visita de inspección por él recibida, y habiendo sido mal clasificado a consecuencia de la misma, una nueva visita varíe aquella clasificación.

b) De ocultación:

1. Cuando en las declaraciones, en los partes de alta o en los dernás documentos presentados a la Administración no se consignen todos los elementos sujetos a contribución.

2. Cuando, declarada una industria, comercio, profesión u ofi54 cio se descubra que, después de comprobada por la Inspección, se han 
introducido $\in \mathrm{n}$ ella. sin declararlas, modificaciones que hagan variar su cuota.

3. Cuando en las declaraciones aparezcan elementos consignados en forma que encierre malicioso deseo de disfrazarlos para sustraerlas en parte a la tributación o disminuir la cuota.

c) De defraudación:

1. Cuando la ocultación sea total.

2. Cuando por haberse sustraído íntegramente al conocimiento de la Administración una base impositiva hayan dejado de liquidarse los correspondientes derechos del Tesoro.

3. Cuando envuelvan falsedad maliciosa o de ellas se derive responsabilidad penal.

4. Cuando el expedientado sea reincidente.

La distinción entre mera omisión, ocultación y defraudación del artículo 96 del Reglamento de Hacienda Municipal es demasiado casuística y prácticamente difícil de llevar a sus últimas consecuencias. Lo esencial es definir la infracción reglamentaria y la defraudación, como vemos en el proyecto de Código de Gobierno y Administración local, cuyo artículo 1.030 dice: "En términos generales, y salvo lo especialmente regulado en este Código para determinadas exacciones, se entenderá que constituyen defraudación los actos u omisiones de los obligados a contribuir por cualquier concepto, 0 de sus representantes legales, con propósito de eludir totalmente o de aminorar el pago de las cuotas o liquidaciones correspondientes, y que constituyen infracciones aquellos actos $u$ omisiones que solamente sean el incumplimiento o el cumplimiento defectuoso de preceptos reglamentarios."

\section{C) Concepto fiscal de la reincidencia.}

Reincidir es volver a caer o incurrir en un error, falta o delito. Reincidencia es acción y efecto de reincidir, reiteración de una misma culpa o defecto; situación que se da en el sujeto activo cuando ha sido condenado con anterioridad por otro $u$ otros de igual o diferente naturaleza que la del que se trata de castigar. La reincidencia "genérica" se da cuando los dos delitos son de diferente naturaleza; la "específica", cuando se repite el mismo delito u otro análogo (reincidencia "estrictu sensu"). Así, pues, el concepto de la reincidencia, que no se precisa hasta fines del siglo XVIII, es concepto de Derecho penal. May modernamente ha sido incorporado al derecho financiero, sin la rigidez propia de las leyes penales y reduciéndolo en cuanto a su extensión. Aquí no cabe sino la reincidencia "específica" como presunción desfavorable al contribuyente. 
En nuestra legislación municipal no se encuentra referencia alguna a este concepto, tan desmenuzado ya en la Administración de la Hacienda pública. Tampoco aparece en el articulado del proyecto de Código de Gobierno y Administración Local.

El concepto fiscal de la reincidencia en nuestra legislación financiera hállase en el artículo 57 del Reglamento de la Inspección, aprobado por Real decreto de 13 de julio de 1926, a cuyo tenor se considerará reincidente al que incurra en ocultación repetida, siempre que los actos origen de la ocultación se refieran a industria, comercio, profesión $\mathrm{u}$ oficio comprendidos en las mismas contribución y tarifa, castigándose como acto de defraudación, es decir, de la misma manera que si la ocultación fuese total, o cuando por haberse sustraído íntegramente al conocimiento de la Administración una base impositiva hayan dejado de liquidarse los correspondientes derechos del Tesoro, o cuando las declaraciones envuelvan falsedad maliciosa o de ellas se derive responsabilidad penal. Casos todos $\epsilon$ stos de defraudación, a los que se aplica las penalidades establecidas en los distintos reglamentos; si bien, por lo general, y desde luego cuando no existe disposición concreta aplicable al caso, tales actos de defraudación se castigan con multa del duplo al triplo de la cuota liquidable.

El Reglamento de la Inspección orientó la actuación inspectora de los tributos por cauces de suavidad y atracción, de manera que al rigor de la penalidad impuesta ha venido a sustituir una labor educadora, persuasiva, encaminada al convencimiento del contribuyente que haya incurrido en defecto en sus relaciones con el Fisco. De conformidad con este principio, la Real orden de 23 de septiembre de 1927 estableció las llamadas "actas de invitación", modelo núm. 14, y dispuso al propio tiempo, con visión justa del límite que debe tener el régimen que regula, que en los casos en que no exista conformidad entre la Inspección y el contribuyente, o cuando éste ofrezca resistencia, o cuando sea reincidente, la Inspección procederá a levantar acta de constancia de hechos, modelo núm. 9, que lleva implícita la imposición de penalidad. La Dirección General de Rentas Públicas, en su circular de 28 de septiembre de 1927, señaló ya la necesidad del informe del jefe de la Inspección respecto a si el contribuyente a que se refiere el "acta de invitación" ha sido o no objeto de expediente o invitación anterior; a que cuando no exista expediente o invitación anterior, esto es, cuando el contribuyente no pueda ser considerado reincidente en la forma determinada por el artículo $57 \mathrm{del}$ repetido Reglamento, el acta de aquella clase será tramitada como 56 un alta o una declaración, y a que, por el contrario, cuando exista 
reincidencia el inspector-jefe devolverá el acta al inspector correspondiente, anulándola y ordenándole que levante otra del modelo 9.

Ante las dudas ofrecidas en la interpretación de estos preceptos, la Dirección General, por su circular de 9 de abril de 1936, y en relación con la contribución sobre las utilidades de la riqueza mobiliaria, añadió, por vía de aclaración y para unificar criterios, que debe considerarse que hay reincidencia, tanto a los efectos de eliminar el acta de invitación como a los de constituir circunstancias calificativas de defraudación o agravante de responsabilidad, en los casos en que, con anterioridad, se hubiera definido por la Administración, en expediente iniciado en actas modelos 9 ó 14, referidas al mismo contribuyente, una obligación tributaria deducida de igual tarifa, número, epígrafe y concepto, y, dentro de éste, "de la misma modalidad de utilidades", entendiendo que ésta existe siempre que se halle establecida norma distinta o especial para la estimación de la base imponible.

De esta forma se fué dulcificando la aplicación del precepto reglamentario, porque aparte la justificación legal, que es evidente, la razón moral y de equidad de este criterio es clara, ya que la labor educadora, que es fundamento del actual régimen de investigación, queda cumplida eficazmente con la invitación que se haga al contribuyente, por una vez. respecto de cada utilidad de las que el mismo está sujeto a declarar, después de lo cual la repetición exacta del mismo hecho o la misma omisión no implica ya desconocimiento de la obligación tributaria.

La presunción no existe, ni puede existir, tratándose de los expedientes instruídos por la Inspección por beneficios extraordinarios sujetos a la contribución excepcional creada por ley de 5 de enero de 1939 y restablecida por la de 17 de octubre de 1941, pues así se deduce de la interpretación legal y lógica de las disposiciones reglamentarias dictadas hasta la fecha, siendo ello, además, congruente con el carácter de esta figura tributaria-excepcional, extraordinaria y transitoria-, llamada a desaparecer cuando así lo estime oportuno el Gobierno, y acerca de cuya gestión la Inspección del Tributo viene ejerciendo una labor educadora y tutelar que por sus circunstancias especiales hácese incompatible con el concepto fiscal de la reincidencia.

Tal es, en definitiva, el criterio de la Inspección General y de la actual Dirección General de Contribuciones Industrial y de Utilidades. 


\section{d) Infracciones reglamentarias y defraudación.}

El derecho vigente señala la distinción entre las infracciones de carácter reglamentario y actos constitutivos de defraudación. Para las primeras, ya el artículo 77 de la ley de 1877 establecía una escala de multas, disponiendo que "las penas que por infracción de las Ordenanzas y reglamentos impongan los Ayuntamientos sólo pueden ser multas que no excedan de 50 pesetas en las capitales de provincia, 25 en las de partido y pueblos de 4.000 habitantes y 15 en los restantes, con el resarcimiento del daño causado e indemnización de gastos, y arresto de un día por duro en caso de insolvencia". A tenor de los artículos 568 del Estatuto Municipal y 278 del Provincial, la defraudación se castiga, por lo general, con multa del duplo al quíntuplo de las cantidades defraudadas, y las infracciones de las Ordenanzas que no constituyen defraudación (reglamentarias), con multas que no exceden de 250 pesetas. La imposición de multas no obsta en ningún caso a la exáción de las cuotas defraudadas y de sus intereses legales. $\mathrm{Ha}$ desaparecido el arresto como equivalente al pago de la multa y en defecto de ésta, por no tener concordantes en el Estatuto los artículos 77 y 114, párrafo primero de la ley Municipal de 1877.

Pero puede ocurrir que los responsables de la defraudación, antes de iniciarse el procedimiento administrativo contrà ellos, hagan a la Administración municipal o provincial las declaraciones necesarias para la exacción de las cuotas defraudadas; en tales casos, no podrán ser multados con cantidad superior al importe de dichas cuotas '(artícuios 569 del E. M. y 279 del E. P.). En los casos de defraudación y en los de infracción reglamentaria, cometidos por el representante legal de un menor o incapacitado, las multas recaerán sobre el representante, limitándose la responsabilidad del menor o incapacitado a las cuotas defraudadas y sus intereses legales, y quedando siempre a salvo su derecho para reclamar de aquél el importe de las cuotas con que se hubiere enriquecido indebidamente y sus intereses; pero esta reducción de las multas será de aplicación al caso en que las declaraciones fueren hechas por el menor o por el incapacitado al llegar a la mayor edad o al cesar la incapacidad, respectivamente (artículos 570 del E. M. y 280 del E. P.).

En el proyecto de Código, las defraudaciones se sancionan con multas hasta el máximo del duplo de lo dejado de percibir, y las infracciones reglamentarias con multas hasta el límite máximo de 500 pesetas (artículo 1.031). 
Pago de las multas.

A tenor del artículo 101 del Reglamento de Hacienda Municipal - 287 del Estatuto. Provincial, las multas que se impongan por incumplimiento de las Ordenanzas de exacciones deberán satisfacerse con el papel creado al efecto por la entidad municipal, correspondiendo al Estado, con arreglo a la Ley del Timbre, el 10 por 100 de su valor. Los residuos serán satisfechos en metálico.

En el proyecto de Código, las multas impuestas por defraudaciones e infracciones se harán efectivas en metálico (artículo 1.035).

Sin perjuicio de la imposición de multas que en cada caso procedan, la omisión de las declaraciones obligatorias por precepto de la ley u Ordenanza autoriza al Ayuntamiento o a la Diputación para fijar, por estimación, las cifras omitidas, en cuanto fueren indispensables para la exacción del gravamen correspondiente (artículos $\mathbf{5 7 1}$ del E. M. y 284 del E. P.).

\section{Derechos contra posibles extralimitaciones de la Administráción.}

Los derechos del contribuyente contra posibles extralimitaciones de la Administración Local hállanse perfectamente definidos y regulados en diversos textos, pero principalmente en el reglamento de procedimiento en materia municipal, y en el de procedimiento en las reclamaciones económicoadministrativas de 29 de julio de 1924 en segundo término. Entre otros extremos, el decreto de 2 de agosto de 1934, modificativo de varios artículos de este reglamento, al desarrollar el apartado f) de la base 6." de la ley de 3 de diciembre de 1932 sobre recurso previo de reposición contra los actos económicoadministrativos, tuvo presente que de una manera general ya estaba establecida la facultad de los contribuyentes de solicitar verbalmente la rectificación de los actos administrativos antes de que se haya verificado el ingreso de las cantidades liquidadas, sin que esto constituya una instancia a efectos de las reclamaciones, e introdujo notables variaciones, tales como la de que el recurso de que se trata será admisible con independencia de que se haya o no efectuado el ingreșo; que la rectificación debe acordarse lo mismo cuando el error se deba a la Administración que cuando sea imputāble al propio contribuyente; que el trámite del recurso de reposición será potestativo para los interesados, pudiendo interponer contra el acto directamente reclamación económicoadministrativa; que este recurso será admitido por lo general si se interpone en forma verbal, aunque también puede formularse por escrito. Todo esto constituía, sin duda, una extraordinaria novedad en beneficio del contribuyente, no siendo de 
menor importancia la que representaba la adición al mismo reglamento de un nuevo capítulo, el XVI, sobre devoluciones de ingresos indebidos, efectuada por el mismo decreto de 2 de agosto de 1934.

Con la publicación de estos textos y del Reglamento de la Inspección de 1926, en la Administración de la Hacienda pública se echó al olvido algo tan interesante como el contenido del número primero del artículo 14 de la Ley de Reforma tributaria de 26 de julio de 1922, que se halla en plena vigencia por no haber sido expresamente derogado por otra ley posterior. Indudablemente a este precepto alude implícitamente la ley de 28 de marzo de 1941 al disponer que el recargo de 10 por 100 en acta de invitación no se aplicará cuando el contribuyente se hallare matriculado con clasificación fijada por la propia Administración en virtud de consulta.

Si el expedientado por la Inspección no aceptase el fallo de la Administración, podrá libremente entablar contra él, en el plazo de quince días, la reclamación económicoadministrativa que corresponda con arreglo al vigente reglamento de procedimientos, aprobado por Real decreto de 29 de julio de 1924. Con arreglo al mismo, capítulo $\mathrm{XV}$, y al Real decreto de 30 de abril de 1923, podrá solicitarse la condonación de la multa impuesta, cuando no tuvo lugar la condonación automática del artículo 63 del Reglamento de la Inspección, entendiéndola, en todo caso, limitada a las dos terceras partes, en virtud del Real decreto de 22 de octubre de 1926.

Garantías análogas ofrece el Derecho municipal. Así, el artículo 97 del Reglamento de.Hacienda Municipal y el 282 del Estatuto Provincial disponen que "los interesados comprendidos en alguno de los casos especificados en el artículo anterior podrán reclamar contra la calificación del hecho o las liquidaciones practicadas, entendiéndose que la reclamación de un contribuyente no cambia la naturaleza de su responsabilidad por ocultación o defraudación, según el carácter de la falta cometida".

\section{Las garantıas, en el Proyecto de Código de Gobierno y Ad-} ministración Local.

Acerca de este particular, el proyecto contiene los preceptos siguientes:

El artículo 1.037, consecuente con el principio general según et cual nadie puede ser condenado sin ser oído, al decir que "en los expedientes de defraudación e infracciones que se tramiten, en su caso, por la Administración se dará vista y audiencia escrita a los interesados, admitiéndoles prueba documental".

"Los alcaldes y presidentes podrán ampliar la prueba y practicar. 
las diligencias que, en su caso, estimen pertinentes para mejor proveer y dictar los fallos."

El artículo 1.038, a cuyo tenor "si iniciado un expediente, y antes de dictarse el fallo; los interesados se conformasen con las actuaciones y con ingresar, en su caso, las cuotas liquidadas en el mismo y sus intereses legales, las penalidades propuestas se reducirán a la cuarta parte".

Según el artículo 63 del Reglamento de la Inspección de la Haciendo pública, el expedientado tiene cinco días de plazo, a contar desde el de la notificación, para aceptar el fallo de la Administración. La aceptación se hará por medio de comparecencia en el expediente, firmada por el interesado o por medio de escrito unido a él, y llevará consigo la condonación automática de las dos terceras partes de la multa impuesta; pero es requisito indispensable para que pueda surtir estos efectos que en el escrito de aceptación o en la diligencia de comparecencia haga el interesado renuncia expresa a utilizar contra aquel fallo todos los recursos, incluso el contenciosoadministrativo. También es preciso que no haya sido declarado defraudador (artículo 65). Otro requisito, según la base 51 de la Contribución Industrial, será el ingreso sin demora.

Como puede observarse, la Hacienda estatal aparece como menos benévola que la local en este proyecto.

$\mathrm{Y}$ finalmente, el 1.039, que ampara al contribuyente contra posibles errores o extralimitaciones de la Administración Local, y cuyo texto es: "Contra los fallos que se dicten en los expedientes de defraudación e infracciones procederán los mismos recursos y en los mismos plazos y circunstancias regulados en este Código para la materia de reclamaciones sobre aplicación y efectividad de exacciones municipales y provinciales."

\section{Conclusión.}

No tenemos la pretensión de haber abordado todos los problemas que la organización del Servicio de Investigación plantea, puesto que escasamente hemos podido enumerar algunos de ellos. Otras cuestiones muy importantes, como, por ejemplo, la denuncia pública, ni siquiera han sido enunciadas, no obstante regirse en la Administración Local por las mismas disposiciones dadas para la Inspección de la Hacienda estatal. Pero hay, indudablemente, a lo largo de este trabajo algunas sugerencias probablemente dignas de ser tomadas en consideración, aspectos de una función que, bien organizada y dirigida, puede proporcionar ingresos legítimos a las Corporaciones locales. 
Llegado el momento de formular conclusiones prácticas, hemos de recordar lo dicho al principio de que no todo lo que es adecuado para el régimen económico del Estado puede tener aplicación a la Provincia y al Municipio. Principalmente llamamos la atención sobre el establecimiento del acta de invitación, que las Administraciones locales pueden utilizar, a nuestro juicio, en uso de las atribuciones que les están conferidas, ya que ningún precepto legal ni reglamentario se opone hoy a ello. En el acta de invitación puede que esté el éxito del servicio de investigación en la Hacienda estatal; y si esto es así, ¿ cómo ha de fallar en la Hacienda local?

El acta de que se trata permite la reducción de los casos de ocultación o de defraudación a casos muy calificados. Como hemos visto, esta forma de actuación en el Estado, que en buenos principios debiera utilizarse únicamente cuando se trata de contribuyentes desconocidos de la Administración, porque respecto de los conocidos compete a ésta una acción coercitiva con sanciones determinadas por las leyes y con medios supletorios para la estimación de las bases impositivas, se ha generalizado de modo extraordinario, hasta el punto que la Inspección de los tributos en la Hacienda estatal rara vez se ve precisada a utilizar el acta modelo 9 con imposición de penalidades.

Después de publicada la Ley de 28 de marzo de 1941, mientras subsista el acta de invitación, puede reflejar no sólo bases desconocidas, sino también las conocidas ya de la Administración, y hásta se admite cuando el contribuyente se halla matriculado por la propia Administración en virtud de consulta. ¿Cabe, por lo tanto, mayor generalidad?

Muy recientemente, por Orden de 15 de octubre del año en curso, se ha reorganizado el Servicio de Investigación de la Riqueza Urbana a base del empleo de las actas de invitación y las de constancia de hechos (modelos 14 y 9), mediante la aplicación a este caso concreto de los principios generales ya conocidos, aunque introduciendo algunas variaciones en la remuneración del personal técnico del Servicio de Valoración Urbana, al que se reconoce el derecho a la gratificación fija, pero no a la eventual. Se ha declarado que el personal facultativo que descubra aumentos de riqueza o compruebe los que han sido descubiertos por otros funcionarios pertenecientes a la Inspección, no tienen derecho al premio proporcional, pues en ningún caso deben ser retribuídos en función directa de los aumentos de riqueza que comprueben. No sucede lo propio, en cambio, cuando el descubrimiento de la ocultación se realiza por otros inspectores, que 
pueden ser retribuídos con ese premio proporcional, ya que no influyen para nada en la estimación de las bases.

Sin embargo, la Hacienda pública no olvida que la conciencia fiscal se forma no sólo por la acción educadora del órgano inspector y con un espíritu transigente y benévolo, sino mediante la imposición de penalidades. Por eso, como hemos visto, siguen existiendo casos en que no cabe el acta modelo 14, que se transforma en acta modelo 9 , y la resolución de los expedientes lleva aparejada la imposición de là sanción aplicable a los ocultadores o defraudadores. El acta de invitación, creada por una Real orden, varió todo el sistema creado por un Decreto de bases desarrolladas en un Reglamento, y como por igual beneficiaba al contribuyente y al Tesoro, ha subsistido, subsiste y probablemente subsistirá durante mucho tiempo; todo el que sea necesario para que esa conciencia fiscal se haya formado.

Supone este régimen la creación de un fondo de inspección análogo al que administra en el Ministerio de Hacienda el Comité Central creado por Real decreto de 30 de marzo de 1926, que, en definitiva, no es sino una Caja especial. ¿Pueden las Diputaciones y Ayuntamientos organizar por sí este fondo o es preciso para ello una disposición de carácter general dictada por el Ministerio de la Gobernación? Seguramente que esto último sería lo más acertado y conveniente. De todas formas, la Dirección General de Administración Local tiene la palabra.

\author{
A. Shura Pacheco \\ Catedrático de la Escuela Nacional \\ de Administración y Estudios Urbanos.
}

